РАЦІОНАЛЬНІ ПАРАМЕТРИ БУРОПІДРИВНИХ РОБІТ ПРИ ПРОВЕДЕННІ ВИРОБОК В УМОВАХ ПрАТ «ЗАПОРІЗЬКИЙ ЗРК»

М.М. Кононенко ${ }^{1 *}$, О.В. Нечит ${ }^{1}$

${ }^{1}$ Національний технічний університет «Дніпровська політехніка», м. Дніпро, Україна

"Відповідальний автор: e-mail: kmn211179@gmail.com

\title{
RATIONAL PARAMETERS OF DRILLING-AND-BLASTING OPERATIONS AT MINE WORKINGS CONSTRUCTION IN THE CONDITIONS OF PJSC "ZAPORIZSKYI IRON-ORE PLANT"
}

\author{
M.M. Kononenko ${ }^{1 *}$, O.V. Nechyt ${ }^{1}$ \\ ${ }^{1}$ Dnipro University of Technology, Dnipro, Ukraine \\ *Corresponding author: e-mail: kmn211179@gmail.com
}

\begin{abstract}
Purpose. Substantiation and choice of rational parameters of drilling-and-blasting operations for mine workings construction with the use of emulsion explosives.

Methods. The tasks were solved by a complex method, which includes the analysis of mining and geological conditions of deposition and development of chambers by means of chamber systems of development with the laying of the produced space, applied technology of drilling and blasting in the course of mining and theoretical studies, which were performed using mathematical methods.

Findings. As a result of the calculations, a new technological solution was developed to substantiate and select rational parameters of drilling and blasting operations with the use of emulsion explosives during preparatory workings, which will allow to carry out resource saving in carrying out tunneling works.

Originality. A new and effective approach is used to determine the location of holes in the bottom of the production, taking into account the energy characteristics of the explosive and the physical and mechanical properties of the rocks.

Practical implications. A technological solution is developed to substantiate and select rational parameters of drilling and blasting operations using emulsion explosives for workings, which will allow to carry out resource saving in the production of mining operations.

Keywords: emulsion explosives, drilling and blasting passport, mining equipment, self-propelled machinery, self-propelled drilling rig, loading and delivery machine
\end{abstract}




\section{1. ВСТУП}

Підземна розробка залізних руд в Україні здійснюється із застосуванням буропідривного способу проведення гірничих виробок [1]. При цьому швидкість проведення виробок залежить від вірного складання та розрахунку параметрів буропідривних робіт (БПР) [2]. Для підвищення безпеки, а також зниження кількості шкідливих газів після вибухових робіт останнім часом стали широко впроваджуватися емульсійні вибухові речовини (ВР) вітчизняного виробництва [3-8]. Які є безпечними в експлуатації та перевершують тротиловмісні ВР за енергетичними характеристиками [9-12].

Високопродуктивне гірничопрохідницьке обладнання та різні методики виконання БПР не принесуть істотного ефекту без розробки паспортів БПР 3 раціональним розташуванням шпурів у вибої, що повинні враховувати характеристики емульсійної ВР [13]. Це є актуальним завданням на сучасному етапі розвитку гірничодобувних підприємств [14-17].

\section{2. АНАЛІЗ ТЕХНОЛОГІЇ ПРОВЕДЕННЯ ВИРОБОК}

В умовах Приватного акціонерного товариства «Запорізький залізорудний комбінат» (ПрАТ «ЗЗРК»), яке видобуває багату залізну руду поверхово-камерною системою розробки із закладанням, щорічно проводиться до 23 тис. м підготовчих і нарізних виробок за допомогою БПР. Застосування на прохідницьких роботах високопродуктивного самохідного обладнання виробництва Швеції, Фінляндії та Словаччини сприяє збільшенню об'ємів підготовчих робіт до 30 тис. м/рік. Це дозволить прискорити темпи підготовки і нарізки нових горизонтів. Але основним стримуючим фактором, який знижує фактичний потенціал гірничопрохідницького обладнання під час проведення гірничих виробок $є$ застосування нераціональних параметрів БПР, а саме застосування ВР, які мають ступінь завершеності реакції вибухового перетворення на $30 \%$ менше у порівнянні з емульсійними ВР, що тягне за собою перевитрату вибухових матеріалів, збільшення трудомісткості заряджання, і як наслідок зниження темпів проведення підготовчих виробок.

Виконавши аналіз паспортів БПР для проведення відкотних штреків лежачого і висячого боків можна зробити наступний висновок, що шпури у вибої виробки мають різні діаметри 43 або 51 мм, а в якості ВР застосовується Амоніт №6 ЖВ, який у порівнянні з емульсійною ВР типу Україніт-П має до $30 \%$ менше ступінь завершеності реакції вибухового перетворення. Кількість шпурів у вибої виробки не змінюється при зміні міцності порід, це говорить про те, що обрано не раціональні та не обгрунтовані параметри БПР. Застосування в якості гірничопрохідницького обладнання гірничих машин різних країн виробників може призвести до збільшення часу простою через різну їх продуктивність. 


\section{3. РЕЗУЛЬТАТИ РОЗРАХУНКУ ПАРАМЕТРІВ БПР}

Головним параметром для проектування паспортів буропідривних робіт при проведенні гірничих виробок є лінія найменшого опору (ЛНО) відбійного шпуру і відстань між шпурами [18]. Далі основним етапом складання паспорту БПР є визначення кількості шпурів для вибою виробки, а також розробка раціональної схеми їх розташування. Головним критерієм, яким користуються дотепер, є кількість шпурів для вибою, яке прямо пропорційне кількості вибухової речовини, необхідного для руйнування певного об'єму гірської маси. Теоретичні основи руйнування гірських порід вибухом широко висвітлені у дослідженнях М.М. Протод'яконова, М.М. Покровського, Е.О. Мінделі, Б.М. Кутузова, М.О. Садовського, В.М. Родіонова та ін. Однак до теперішнього часу не розроблено загальноприйнятої методики розрахунку основних параметрів БПР, яка дозволяла б отримувати придатні для практики результати, які не вимагали б проведення пробних вибухів і перевірочних розрахунків.

Тому на сьогоднішній день широко використовується спрощена методика, яка зводиться до визначення раціональної місткості ВР в одному шпурі i встановленого практикою іiі питомої витрати. На підставі цих показників визначається кількість шпурів для вибою виробки. Далі обирають тип вруби, який розміщується в основному в геометричному центрі виробки, а в решті площі перетину розподіляють інші групи шпурів [19-21].

Важливою умовою високої ефективності проведення виробок $є$ правильний вибір комплекту шпурів, що забезпечує максимальний коефіцієнт їх використання, який визначає швидкість проведення виробок. Раціональні параметри БПР, такі, як тип врубу, схема розташування і число відбійних шпурів, тип ВР і величина заряду, залежать від конкретних гірничогеологічних умов. У сучасній практиці широко використовуються типи врубів, які класифікуються за розташуванням врубових шпурів щодо площині вибою: похилі вруби (відривної дії) і прямі вруби (дрібної дії). Останні типи врубів використовуються у міцних монолітних породах.

Місце розташування врубу робить істотний вплив на показники БПР. Згідно офіційно діючих на українських гірничих підприємствах інструкцій, вруб розташовують збоку, вгорі, внизу або у центрі вибою виробки. Після вибурювання врубових шпурів приступають до буріння відбійних шпурів, основним параметром яких є величина відбійного шару $W$, так звана ЛНО на новостворену поверхню оголення. Параметр ЛНО, як правило, уточняється після аналізу результатів трьох пробних вибухів.

На практиці раціональні відстані між шпурами $a$ розраховуються у вигляді $a=K W$, причому $K=1,0-1,3$ для відбійних шпурів, $K=0,75$ - для контурних підошви, $K=0,85$ для контурних покрівлі, $K=0,95$ - для контурних 3 боків виробки. Проектування схеми розташування відбійних шпурів $\epsilon$ найбільш трудомісткою операцією. Широке поширення на практиці отримали два способи розташування відбійних шпурів: за сіткою і за відбійними контурами. При своїй простоті обидва способи мають ряд суттєвих недоліків. Так, при розташуванні шпурів за сіткою нераціонально розташовуються шпури у покрівлі виробки, а за відбійними контурами, навпаки, з боків і пі- 
дошви. Спроби комбінування цих способів призводять до порушення $W$ між суміжними рядами шпурів і складнощів при бурінні вибоїв переносними перфораторами. У свою чергу, нераціональне розташування шпурів у вибої виробки призводить до перевитрати вибухових матеріалів, бурового інструменту, а у деяких випадках і до зниження безпеки гірничих робіт.

Порівняльні розрахунки паспортів БПР показали, що від правильного вибору способу розташування шпурів для різних форм і площ поперечного перерізу виробок залежить ступінь раціональності розташування шпурів i, відповідно, їх кількість.

Авторами у роботі [22] пропонується наступна послідовність вирішення основних задач проектування паспортів БПР з урахування параметру оптимізації розміщення шпурів:

1. Визначення площ для розміщення різних груп шпурів (вруби, відбійних та контурних шпурів);

2. Визначення координат приконтурних шпурів;

3. Визначення координат відбійних шпурів ;

4. Проектування паспорту БПР на основі розрахованих координат шпурів.

Подальший розвиток методики розрахунку і складання паспортів БПР висвітлено у роботах $[23,24]$ і подано простішою інженерною мовою. Розрахунок паспорту БПР для проведення виробок включає в себе наступні основні етапи:

- розрахунок загальної кількості ВР на вибій;

- розрахунок кількості шпурів на вибій з урахуванням зайнятими ними площ (зон);

- розташування шпурів у вибої;

- розрахунок заряду ВР на шпур;

- розрахунок загального фактичного використання ВР на вибій.

Представлена вище методика розрахунку параметрів БПР при проведенні гірничих виробок призначена для використання тротиловмісних ВР. Авторами у роботі [25] розроблено нову методику розрахунку параметрів БПР при проведенні підземних гірничих виробок з використанням емульсійних ВР типу Україніт. Сутність методики полягає у визначенні коефіцієнту відносної працездатності емульсійної ВР типу Україніт з урахуванням ступеня завершеності реакції вибухового перетворення та реалізації швидкості детонації, що дозволяє визначити необхідну кількість ВР на вибій. Встановлені закономірності дозволяють визначити швидкість детонації в залежності від щільності та діаметру заряду, які змінюється за степеневим законом. Це дозволило авторам вдосконалити закономірності визначення розмірів зон зминання і тріщиноутворення, які утворюються навколо шпурів з урахуванням енергетичних характеристик емульсійної ВР Україніт і фізико-механічних властивостей порід.

Тому для обгрунтування раціональних параметрів БПР при проведенні підготовчих гірничих виробок необхідно виконати розрахунок паспортів БПР при використанні патронованої ВР типу Амоніт № 6 ЖВ і Україніт-П$\mathrm{CA}$, для наступних гірничо-геологічних умов: виробка - відкотний штрек лежачого боку гор. 940 м, ширина виробки - 3,75 м, висота виробки - 3,35 м, довжина виробки -500 м, коефіцієнт міцності порід $f=5-14$, середня міц- 
ність $-f=10$, діаметр шпуру - 43 мм, глибина комплекту шпурів $-2,8$ м, установка бурильна шахтна - DD311-40, шахтна вантажно-доставна машина - LH409E.

За результатами розрахунків паспортів БПР складено схему розташування шпурів у вибої виробки і конструкцію врубу, поданих на рис. 1.
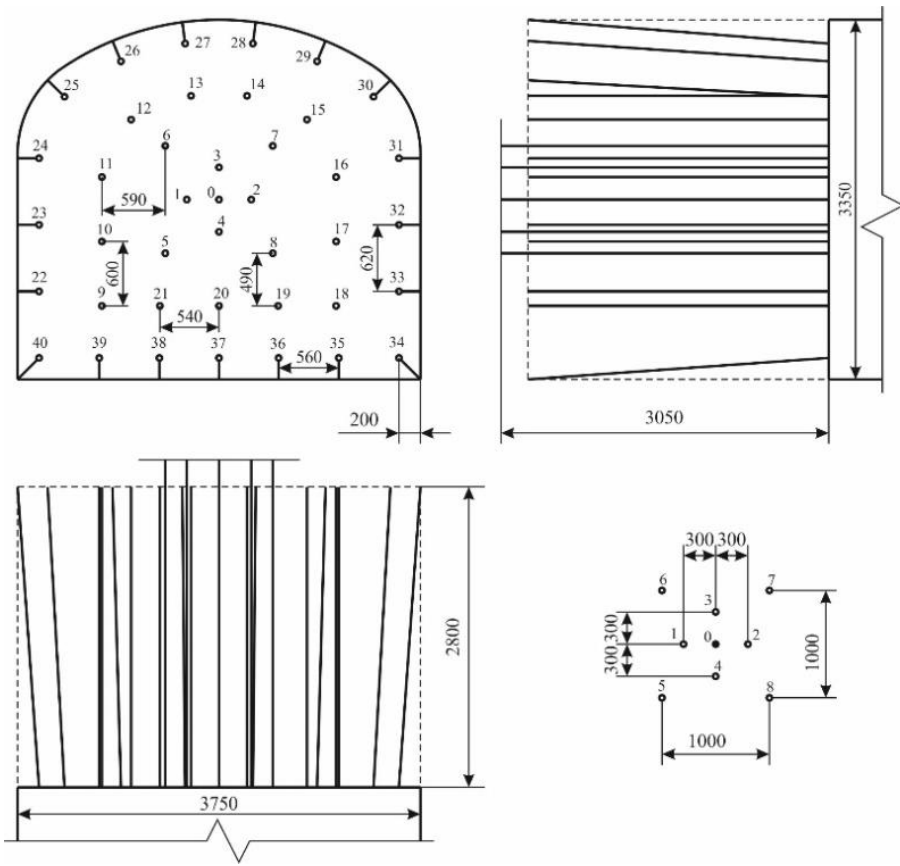

6
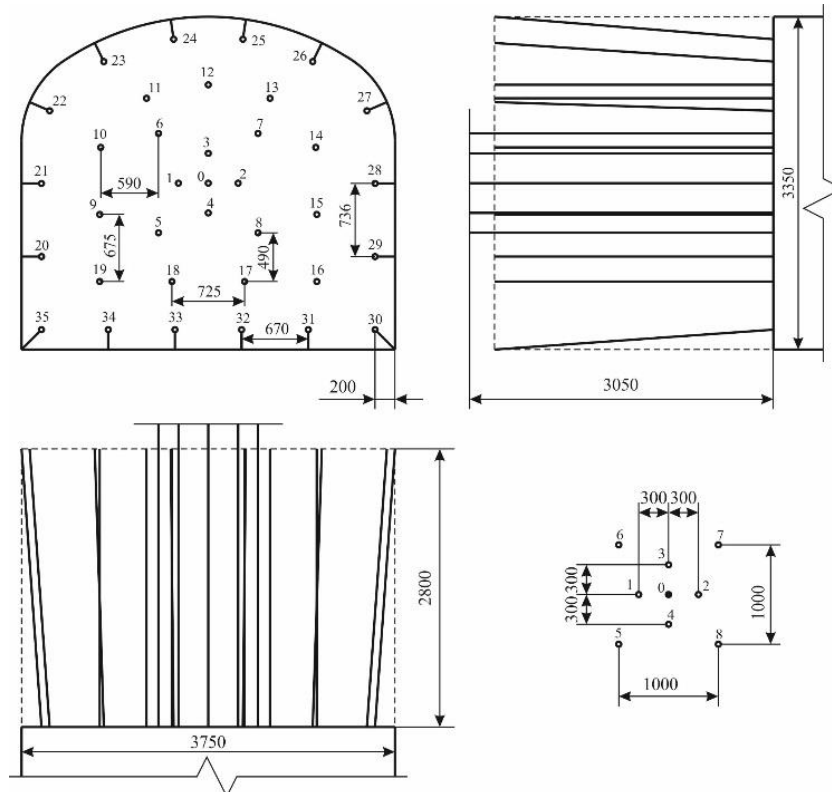

Рисунок 1. Схема розташування шиурів і конструкція врубу при проведенні штреку лежачого боку при використанні ВР типу Амоніт № 6 ЖВ (a) та Украӥніт-П-СА (б) 
Отримані результати розрахунку паспортів БПР, трудомісткості і витрати матеріалів при різних типах ВР, подано в табл. 1.

Таблиця 1. Технічні показники паспортів БПР при різних ВР

\begin{tabular}{|l|l|c|c|c|}
\hline $\begin{array}{c}\text { № } \\
\text { п/п }\end{array}$ & \multicolumn{1}{|c|}{$\begin{array}{c}\text { Показники } \\
\text { виміру }\end{array}$} & $\begin{array}{c}\text { Паспорт } \\
\text { БПР } \\
\text { Амоніт } \\
\text { № 6 ЖВ }\end{array}$ & $\begin{array}{c}\text { Паспорт } \\
\text { БПР } \\
\text { Україніт- } \\
\text { П-СА }\end{array}$ \\
\hline 1 & Площа поперечного перерізу & м $^{2}$ & 11,5 & 11,5 \\
\hline 2 & Коефіцієнт міцності порід & $f$ & 10 & 10 \\
\hline 3 & Бурильна установка DD311-40 & шт. & 1 & 1 \\
\hline 4 & Вантажна машина LH409Е & шт. & 1 & 1 \\
\hline 5 & Діаметр шпурів & мм & 43 & 43 \\
\hline 6 & Число шпурів на цикл & шт. & 41 & 36 \\
\hline 7 & Глибина шпурів & м & 2,8 & 2,8 \\
\hline 8 & Число шпуро-метрів на цикл & М & 117,05 & 103,5 \\
\hline 9 & КВШ шпурів & $\eta$ & 0,9 & 0,9 \\
\hline 10 & Витрати ВР & кг & 14520 & 13720 \\
\hline 11 & Витрати ЕД & шт. & 8000 & 7000 \\
\hline 12 & Відхід вибою за цикл & м & 2,5 & 2,5 \\
\hline 15 & Вихід породи за цикл & м & 28,75 & 28,75 \\
\hline 16 & Витрати електроенергіі & кВт·год & 45800 & 40050 \\
\hline 17 & Витрати коронок & шт. & 36 & 36 \\
\hline 18 & Витрати бурової стали & шт. & 10 & 10 \\
\hline 19 & Витрати анкерів & шт. & 2500 & 2500 \\
\hline 20 & Кількість змін & змін & 200 & 200 \\
\hline & & & \\
\hline
\end{tabular}

Виконавши аналіз технічних показників паспортів БПР при використанні різних типів ВР можна зробити висновок, що при використанні для проведення виробок ВР типу Україніт-П-СА зменшується кількість шпурів у вибої виробки і відповідно зменшується сумарна їх довжина. Це призводить до зменшення часу на їх буріння і заряджання. Як видно з табл. 1 витрати ВР, засобів ініціювання зарядів, а також матеріалів не перевищує 10\%.

Подальші економічні розрахунки, які виконувались за основними статтями калькуляції витрат, дозволили встановити, що при проведенні польового відкотного штреку лежачого боку гор. 940 м з використання емульсійної ВР типу Україніт-П-СА дозволить знизити собівартість проведення 1 м виробки до $11 \%$.

\section{4. ВИСНОВКИ}

Проведений аналіз технічних показників за виконаними розрахунками і складеними паспортами БПР при використанні різних ВР, дозволило визначити раціональний тип ВР, що дозволить застосувати технологічне рішення в області проведення підготовчих виробок буропідривним способом і посприяє підвищенню безпеки праці робітників і ресурсозбереженню. Застосу- 
вання емульсійної ВР типу Україніт-П-СА дозволить зменшити кількість шпурів у вибої виробки до 12\% у порівнянні з використанням ВР типу Амоніт № 6 ЖВ.

Витрати вибухових матеріалів при використанні паспорту БПР при застосуванні ВР Україніт-П-СА зменшиться до 6\%. Ці показники свідчать про необхідність переходу до застосування емульсійної ВР типу Україніт-П-СА при проведенні підготовчих і нарізних виробок буропідривним способом, а також застосування на прохідницьких роботах високопродуктивного гірничо-шахтного прохідницького обладнання. Очікуваний економічний ефект, отриманий у результаті техніко-економічного порівняння за основними статтями калькуляції витрат, свідчить про доцільність впровадження розробленого технологічного рішення. Застосування запропонованої вибухівки при проведенні виробок в умовах ПрАТ «ЗЗРК» дозволить знизити собівартість проведення 1 м виробки до $11 \%$.

\section{СПИСОК ЛІТЕРАТУРИ}

1. Хоменко, О., Кононенко, М., Владыко, А., \& Мальцев, Д. (2011). Горнорудное дело Украины в сети Интернет. Д.: НГУ.

2. Кутузов, Б.Н., \& Андриевский, А.П. (2003). Новая теория и новые технологии разрушения горных пород удлиненныли зарядами взрыьватых веществ. Новосибирск: Наука.

3. Khomenko, O., Kononenko, M., \& Myronova, I. (2013). Blasting works technology to decrease an emission of harmful matters into the mine atmosphere. Mining Of Mineral Deposits, 231-235. http://doi.org/10.1201/b16354-43

4. Mironova, I., \& Pavlichenko, A. (2013). Analysis of air pollution levels during underground ore mining. Mining of Mineral Deposits, 7(3), 261-266. http://doi.org/10.15407/mining07.03.261

5. Gorova, A., Kolesnyk, V., \& Myronova, I. (2014). Increasing of environmental safety level during underground mining of iron ores. Mining of Mineral Deposits, 8(4), 473-479. http://doi.org/10.15407/mining08.04.473

6. Mironova, I., \& Borysovs'ka, O. (2014). Defining the parameters of the atmospheric air for iron ore mines. Progressive Technologies of Coal, Coalbed Methane, and Ores Mining, 333-339. http://doi.org/10.1201/b17547-57

7. Myronova, I. (2015). The level of atmospheric pollution around the iron-ore mine. New Developments in Mining Engineering 2015, 193-197. http://doi.org/10.1201/b1990135

8. Myronova, I. (2015). Changing of biological traits of winter wheat that vegetate near emission source of iron-ore mine. Mining of Mineral Deposits, 9(4), 461-468. http://doi.org/10.15407/mining09.04.461

9. Kholodenko, T., Ustimenko, Y., Pidkamenna, L., \& Pavlychenko, A. (2014). Ecological safety of emulsion explosives use at mining enterprises. Progressive Technologies of Coal, Coalbed Methane, and Ores Mining, 255-260. http://doi.org/10.1201/b17547-45

10. Kholodenko, T., Ustimenko, Y., Pidkamenna, L., \& Pavlychenko, A. (2015). Technical, economic and environmental aspects of the use of emulsion explosives by ERA brand in underground and surface mining. New Developments in Mining Engineering 2015, $211-$ 219. http://doi.org/10.1201/b19901-38 
11. Khomenko, O., Kononenko, M., \& Myronova, I. (2017). Ecologic-and-technical aspects of iron-ore underground mining. Mining of mineral deposits, 11(2), 59-67 https://doi.org/10.15407/mining11.02.059

12. Khomenko, O., Kononenko, M., Myronova, I., \& Sudakov, A. (2018). Increasing ecological safety during underground mining of iron-ore deposits. Naukovyi Visnyk Natsionalnoho Hirnychoho Universytetu, (2), 29-38. http://doi.org/10.29202/nvngu/2018$2 / 3$

13. Khomenko, O., Kononenko, M., Myronova, I., \& Savchenko, M. (2019). Application of the emulsion explosives in the tunnels construction. E3S Web of Conferences, 123, 01039. http://doi.org/10.1051/e3sconf/201912301039

14. Гринев, В.Г., \& Хорольский, А.А. (2017). Система поддержки принятия решений при разработке месторождений полезных ископаемых. Горно-геологический журнал, 51(3), 18-24.

15. Хорольский, А.А., \& Гринев, В.Г. (2018). Выбор сценария освоения месторождений полезных ископаемых. Геология и охрана недр, (3), 68-75.

16. Гріньов, В.Г., Хорольський, А.О., \& Каліущенко, О.П. (2019). Розроблення екологічних сценаріїв ефективного освоєння цінних родовищ корисних копалин. $\mathrm{Mi}$ неральні ресурси Украӥни, (2), 46-50. http://doi.org/10.31996/mru.2019.2.46-50

17. Khorolskyi, A., Hrinov, V., Mamaikin, O., \& Demchenko, Y. (2019). Models and methods to make decisions while mining production scheduling. Mining of Mineral Deposits, 13(4), 53-62. http://doi.org/10.33271/mining13.04.053

18. Шевцов, Н.Р., Таранов, П.Я., Левит, В.В., \& Гудзь, А.Г. (2003). Разрушение горных пород взрывом. Донецк.

19. Меркулов, А.В., Сильченко, Ю.А., \& Скориков, В.А. (2003). Проектирование паспортов буровзрывных работ при проходке горных выработок. Новочеркасск: ЮРГТУ.

20. Оника, С.Г., \& Стасевич, В.И. (2005). Разрушение горных пород взрывом. Минск: БНТУ.

21. Оника, С.Г., Стасевич, В.И., \& Ковалева, И.М. (2016). Разрушение горных пород взрывом. Минск: БНТУ.

22. Khomenko, O., Rudakov, D., \& Kononenko, M. (2011). Automation of drill and blast design. Technical And Geoinformational Systems In Mining, 271-275. http://doi.org/10.1201/b11586-45

23. Симанович, Г., Хоменко, О., \& Кононенко, М. (2014). Руйнування гірських порід вибухом. Д.: НГУ.

24. Khomenko, O., Kononenko, M., \& Savchenko, M. (2018). Technology of underground mining of ore deposits. http://doi.org/10.33271/dut.001

25. Kononenko, M., Khomenko, O., Savchenko, M., \& Kovalenko, I. (2019). Method for calculation of drilling-and-blasting operations parameters for emulsion explosives. Mining Of Mineral Deposits, 13(3), 22-30. https://doi.org/10.33271/mining13.03.022

\section{REFERENCES}

1. Khomenko, O., Kononenko, M., Vladyko, A., \& Mal'tsev, D. (2011). Gornorudnoe delo Ukrainy v seti Internet. D.: NGU.

2. Kutuzov, B.N., \& Andrievskiy, A.P. (2003). Novaya teoriya i novye tekhnologii razrusheniya gornykh porod udlinennymi zaryadami vzryvchatykh veshchestv. Novosibirsk: Nauka.

3. Khomenko, O., Kononenko, M., \& Myronova, I. (2013). Blasting works technology to decrease an emission of harmful matters into the mine atmosphere. Mining Of Mineral Deposits, 231-235. http://doi.org/10.1201/b16354-43 
4. Mironova, I., \& Pavlichenko, A. (2013). Analysis of air pollution levels during underground ore mining. Mining of Mineral Deposits, 7(3), 261-266. http://doi.org/10.15407/mining07.03.261

5. Gorova, A., Kolesnyk, V., \& Myronova, I. (2014). Increasing of environmental safety level during underground mining of iron ores. Mining of Mineral Deposits, 8(4), 473-479. http://doi.org/10.15407/mining08.04.473

6. Mironova, I., \& Borysovs'ka, O. (2014). Defining the parameters of the atmospheric air for iron ore mines. Progressive Technologies of Coal, Coalbed Methane, and Ores Mining, 333-339. http://doi.org/10.1201/b17547-57

7. Myronova, I. (2015). The level of atmospheric pollution around the iron-ore mine. New Developments in Mining Engineering 2015, 193-197. http://doi.org/10.1201/b1990135

8. Myronova, I. (2015). Changing of biological traits of winter wheat that vegetate near emission source of iron-ore mine. Mining of Mineral Deposits, 9(4), 461-468. http://doi.org/10.15407/mining09.04.461

9. Kholodenko, T., Ustimenko, Y., Pidkamenna, L., \& Pavlychenko, A. (2014). Ecological safety of emulsion explosives use at mining enterprises. Progressive Technologies of Coal, Coalbed Methane, and Ores Mining, 255-260. http://doi.org/10.1201/b17547-45

10. Kholodenko, T., Ustimenko, Y., Pidkamenna, L., \& Pavlychenko, A. (2015). Technical, economic and environmental aspects of the use of emulsion explosives by ERA brand in underground and surface mining. New Developments in Mining Engineering 2015, $211-$ 219. http://doi.org/10.1201/b19901-38

11. Khomenko, O., Kononenko, M., \& Myronova, I. (2017). Ecologic-and-technical aspects of iron-ore underground mining. Mining of mineral deposits, 11(2), 59-67 https://doi.org/10.15407/mining11.02.059

12. Khomenko, O., Kononenko, M., Myronova, I., \& Sudakov, A. (2018). Increasing ecological safety during underground mining of iron-ore deposits. Naukovyi Visnyk Natsionalnoho Hirnychoho Universytetu, (2), 29-38.

http://doi.org/10.29202/nvngu/2018-2/3

13. Khomenko, O., Kononenko, M., Myronova, I., \& Savchenko, M. (2019). Application of the emulsion explosives in the tunnels construction. E3S Web of Conferences, 123, 01039. http://doi.org/10.1051/e3sconf/201912301039

14. Grinev, V.G., \& Khorol'skiy, A.A. (2017). Sistema podderzhki prinyatiya resheniy pri razrabotke mestorozhdeniy poleznykh iskopaemykh. Gorno-geologicheskiy zhurnal, 5l(3), 18-24.

15. Khorol'skiy, A.A., \& Grinev, V.G. (2018). Vybor stsenariya osvoeniya mestorozhdeniy poleznykh iskopaemykh. Geologiya i okhrana nedr, (3), 68-75.

16. Hrinov, V.H., Khorolskyi, A.O., \& Kaliushchenko, O.P. (2019). Rozroblennia ekolohichnykh stsenariiv efektyvnoho osvoiennia tsinnykh rodovyshch korysnykh kopalyn. Mineralni resursy Ukrainy, (2), 46-50. http://doi.org/10.31996/mru.2019.2.46-50

17. Khorolskyi, A., Hrinov, V., Mamaikin, O., \& Demchenko, Y. (2019). Models and methods to make decisions while mining production scheduling. Mining of Mineral Deposits, 13(4), 53-62. http://doi.org/10.33271/mining13.04.053

18. Shevtsov, N.R., Taranov, P.Ya., Levit, V.V., Gudz', A.G. (2003). Razrushenie gornykh porod vzryvom. Donetsk.

19. Merkulov, A.V., Sil'chenko, Yu.A., \& Skorikov, V.A. (2003). Proektirovanie pasportov burovzryvnykh rabot pri prokhodke gornykh vyrabotok. Novocherkassk: YuRGTU.

20. Onika, S.G., \& Stasevich, V.I. (2005). Razrushenie gornykh porod vzryvom. Minsk: BNTU. 
21. Onika, S.G., Stasevich, V.I., \& Kovaleva, I.M. (2016). Razrushenie gornykh porod vzryvom. Minsk: BNTU.

22. Khomenko, O., Rudakov, D., \& Kononenko, M. (2011). Automation of drill and blast design. Technical And Geoinformational Systems In Mining, 271-275. http://doi.org/10.1201/b11586-45

23. Symanovych, H., Khomenko, O., Kononenko, M. (2014). Ruinuvannia hirskykh porid vybukhom. D.: NHU.

24. Khomenko, O., Kononenko, M., \& Savchenko, M. (2018). Technology of underground mining of ore deposits. http://doi.org/10.33271/dut.001

25. Kononenko, M., Khomenko, O., Savchenko, M., \& Kovalenko, I. (2019). Method for calculation of drilling-and-blasting operations parameters for emulsion explosives. Mining Of Mineral Deposits, 13(3), 22-30. http://doi.org/10.33271/mining13.03.022

\section{ABSTRACT (IN UKRAINIAN)}

Мета. Обгрунтування і вибір раціональних параметрів буропідривних робіт для проведення виробок при застосуванні емульсійних вибухових речовин.

Методика. Поставлені задачі вирішувалися комплексним методом, що включає аналіз гірничо-геологічних умов залягання покладу і відпрацювання камер за допомогою камерних систем розробки із закладенням виробленого простору, застосовуваної технології буропідривних робіт при проведенні гірничих виробок і теоретичні дослідження, які виконувалися за допомогою математичного методу.

Результати. У результаті виконаних розрахунків було розроблено нове технологічне рішення 3 обгрунтування та вибору раціональних параметрів буропідривних робіт з використанням емульсійних вибухових речовин при проведенні підготовчих виробок, яке дозволить здійснити ресурсозбереження при провадженні прохідницьких робіт.

Наукова новизна. Використано новий та ефективний підхід до визначення параметрів розташування шпурів у вибої виробки з урахуванням енергетичних характеристик вибухової речовини та фізико-механічних властивостей порід.

Практична цінність. Розроблено технологічне рішення 3 обгрунтування i вибору раціональних параметрів буропідривних робіт із використанням емульсійних вибухових речовин для проведення виробок, яке дозволить здійснити ресурсозбереження при виробництві гірничопрохідницьких робіт.

Ключові слова: емульсійні вибухові речовини, паспорт буропідривних робіт, гірничопрохідницьке обладнання, самохідна техніка, самохідна бурова установка, вантажно-доставна машина

\section{ABSTRACT (IN RUSSIAN)}

Цель. Обоснование и выбор рациональных параметров буровзрывных работ для проведения выработок при применении эмульсионных взрывчатых веществ.

Методика. Поставленные задачи решались комплексным методом, включающим анализ горно-геологических условий залегания залежи и отработки камер с помощью камерных систем разработки с закладкой выработанного про- 
странства, применяемой технологии буровзрывных работ при проведении горных выработок и теоретические исследования, выполнялись с помощью математического метода.

Результаты. В результате выполненных расчетов было разработано новое технологическое решение по обоснованию и выбору рациональных параметров буровзрывных работ с использованием эмульсионных взрывчатых веществ при проведении подготовительных выработок, которое позволит осуществить ресурсосбережения при производстве проходческих работ.

Научная новизна. Использован новый и эффективный подход к определению параметров расположения шпуров в забое выработки с учетом энергетических характеристик взрывчатого вещества и физико-механических свойств пород.

Практическая ценность. Разработаны технологическое решение по обоснованию и выбору рациональных параметров буровзрывных работ с использованием эмульсионных взрывчатых веществ для проведения выработок, которое позволит осуществить ресурсосбережение при производстве горнопроходческих работ.

Ключевые слова: эмульсионные взрывчатые вещества, паспорт буровзрывных работ, горнопроходческое оборудования, самоходная техника, самоходная буровая установка, погрузочно-доставочная машина

\section{ABOUT AUTHORS}

Kononenko Maksym, Candidate of Technical Science, Associated Professor, Dnipro University of Technology, Associate Professor of the Mining Engineering and Education Department, 19 Yavornytskoho Ave., Dnipro, Ukraine, 49005, E-mail: kmn211179@gmail.com

Nechyt Oleksiy, Master of the Mining Engineering and Education, Dnipro University of Technology, 19 Yavornytskoho Ave., Dnipro, Ukraine, 49005, E-mail: aleks.nechet.ua@gmail.com 